(c) Elsevier/INRA

Original article

\title{
Distribution and sources of variability of sister-chromatid exchange frequencies in cattle*
}

\author{
$\mathrm{J}_{\text {Catalán }}{ }^{1}, \mathrm{C}_{\text {Moreno }}{ }^{2}, \mathrm{MV}$ Arruga ${ }^{1}$ \\ 1 Laboratory of Cytogenetics ; \\ 2 Quantitative Genetics Unit, Veterinary Faculty, Miguel Servet, 177, \\ 50013-Zaragoza, Spain
}

(Received 25 August 1993; accepted 12 October 1993)

\begin{abstract}
Summary - The spontaneous incidence of sister-chromatid exchange (SCE) was investigated in a group of cattle, composed of 24 animals of both sexes belonging to different breeds, ages and farms. The work was carried out following a randomized block design. The mean value of SCEs/cell was $5.77 \pm 0.082$ using $5 \mu \mathrm{g} / \mathrm{ml}$ of bromodeoxyuridine (BrdU). The distribution of SCE frequency fits the Poisson model fairly well, although the negative binomial model also gave a good representation of exchange distribution. Among the analyzed sources of variability, group, animal and treatment of BrdU factors showed significant effects. A newly introduced BrdU treatment demonstrated that the number of BrdU molecules available per cell has little influence on SCE rates in relation to its molarity.
\end{abstract}

sister-chromatid exchange / distribution frequency / bromodeoxyuridine / cattle

Résumé - Distribution et sources de variation des fréquences d'échange entre chromatides-sœurs chez les bovins. L'incidence spontanée des échanges entre chromatides-sœurs (ECS) a été étudiée chez 24 bovins de différents sexes, races, âges et exploitations. L'étude a été menée suivant un dispositif en blocs randomisés. Le nombre moyen ECS/cellule a été de 5,77 $\pm 0,082$ en utilisant $5 \mu \mathrm{g} / \mathrm{ml}$ de bromodéoxyuridine (BrdU). La distribution de fréquence des ECS suit principalement un modèle de Poisson, bien qu'un modèle binomial négatif donne aussi une bonne représentation de la distribution. Parmi les sources de variation analysées, les facteurs groupe, animal et traitement du BrdU ont montré des effets significatifs. Un traitement de BrdU introduit récemment a montré que le nombre de molécules de BrdU disponibles par cellule a une légère influence sur le taux d'ECS en relation avec sa molarité.

échange entre chromatides-sœurs / distribution de fréquence / bromodéoxyuridine / bovin

${ }^{*}$ Project supported by CICYT n GAN 91-1327. 


\section{INTRODUCTION}

Sister-chromatid exchange (SCE) analysis has proved to be a valuable procedure for the investigation of the effects of chemical and physical agents on genetic material (Takehisa, 1982; Wulf, 1990). In the field of domestic animals, articles on SCE assay as a mutagenic test are scarce (Arruga et al, 1992) and mainly focus on either the description of SCE frequencies (Di Berardino and Shoffner, 1979; McFee and Sherrill, 1983; Leibenguth and Thiel, 1986; Iannuzzi et al, 1990) or, more recently, the influence of different factors (Iannuzzi et al, 1991). Furthermore, although recent collaborative efforts have been made on humans to set some basic guidelines (Nordic Study Group, 1990a, 1990b; Sorsa et al, 1992), methodological questions have not been clearly solved, such as the determination of the number of subjects to be assigned to each group and the number of mitoses to be analyzed per subject, or the determination of differences to be shown as significant (Hirsch et al, 1984). Logically, the answers to these questions depend upon the variation that exists for SCEs and upon the purpose of the investigation.

In order to contribute to the resolution of these questions in cattle, the distribution of baseline SCEs, as well as different variation sources, were investigated in this work. Likewise, a new bromodeoxyuridine treatment was introduced in order to minimize the residual variability and improve the accuracy of this assay. In the Materials and Methods section the cytogenetic methods and the chosen experimental design are described. The results are compared with those obtained by other authors on distribution of SCE frequencies and sources of variation.

\section{MATERIALS AND METHODS}

\section{Subjects}

A total of 24 healthy animals were analyzed, 9 females and 15 males, from 3 different farms and belonging to 4 breeds and 3 different age groups.

\section{Cytogenetic techniques}

Peripheral blood lymphocytes were cultured and harvested following the standard technique (Basrur and Gilman, 1964). A final concentration of $7 \times 10^{5}$ lymphocytes per $\mathrm{ml}$ was added to the culture medium RPMI 1640 (Flow) with $15 \%$ fetal bovine serum (Sero-lab), $1 \%$ antibiotic-antimicotic (GIBCO) and $2 \%$ phytohaemagglutinin (Wellcome). All cultures were set up in duplicate, grown in the dark, and harvested following $72 \mathrm{~h}$ incubation at $38^{\circ} \mathrm{C}$ including a final $1.5 \mathrm{~h}$ colchicine treatment $(0.05 \mu \mathrm{g} / \mathrm{ml}$ final concentration).

Bromodeoxyuridine (BrdU) acted for the last $26 \mathrm{~h}$ of the culture and was added to a final concentration of $5 \mu \mathrm{g} / \mathrm{ml}(16 \mu \mathrm{M})$ for cultures of treatment 1 and to a variable concentration for cultures of treatment 2 , so that the latter received the same number of BrdU molecules per cell. Therefore, a cellular counting at $46 \mathrm{~h}$ of culture was introduced, to adjust the amount of BrdU added per cell. Since there is no previous work in which this method is used, we had to create our own adjustment criterion. Thus, a great majority of cells were assumed to have finished 
2 replicating cycles at $46 \mathrm{~h}$ and, consequently, the number of lymphocytes present at this time would be $28 \times 10^{5}$ lymphocytes $/ \mathrm{ml}$. In order to put this method on the same level as treatment 1 , a BrdU concentration of $5 \mu \mathrm{g} / \mathrm{ml}$ was added to these cells after $46 \mathrm{~h}$, resulting in a ratio of $0.18 \mu \mathrm{g}$ BrdU per $10^{5}$ lymphocytes.

The slides were aged at least $24 \mathrm{~h}$ before staining with a modification of the "fluorescence plus Giemsa" technique (Perry and Wolff, 1974). For each treatment, 25 mitoses from each duplicate culture were analyzed for SCE, ie 50 cells per treatment were analyzed. Proliferation rate index (PRI) was calculated from 200 mitoses per treatment, following the calculations of Ivett and Tice (1982).

\section{Experimental design}

In order to study the character number of SCEs, which is expressed as the number of $\mathrm{SCE} /$ cell, a randomized block design was chosen according to the following model:

$$
y_{i j k l}=\mu+G_{i}+A_{i j}+T_{k}+\left(G_{i}+A_{i j}\right) T_{k}+e_{i j k l}
$$

where:

$$
\begin{aligned}
& \mu=\text { general mean; } \\
& G_{i}=\text { group effect; } \\
& A_{i j}=\text { animal within group effect; } \\
& T_{k}=\text { treatment effect; } \\
& \left(G_{i}+A_{i j}\right) T_{k}=\text { individual (block) } \times \text { treatment interaction; } \\
& e_{i j k l}=\text { residual }
\end{aligned}
$$

The group effect is defined as a fixed effect and includes controlled factors which can influence the analyzed character, ie sex, breed, age and farm. We define 8 levels, each of which includes 3 individuals belonging to the same sex, age group, breed and farm. Furthermore, each individual receives $2 \mathrm{BrdU}$ treatments. Animal and treatment effects are defined as random and fixed effects, respectively.

The model here presented was fitted using the HARVEY program (version 1987). On the other hand, the comparison of residual variances obtained from the 2 treatments was done by an $F$-test. Finally, the relationship between SCE and PRI values is studied by a simple regression analysis.

\section{RESULTS}

The average frequencies of SCEs as well as the number of analyzed cells, range and proliferation rate indexes are given in table I.

The application of the analysis of variance to the previously established model showed the following result: group, animal and treatment factors had a significant effect, as did the animal-treatment interaction, while the group-treatment interaction was not significant. The group-treatment interaction was thus pooled with the animal-treatment interaction. Later, the residuals of the variable under study, calculated as deviations from individual-treatment means, were evaluated by the normality and homogeneity of variance tests (Peña, 1988). The frequency distribution 


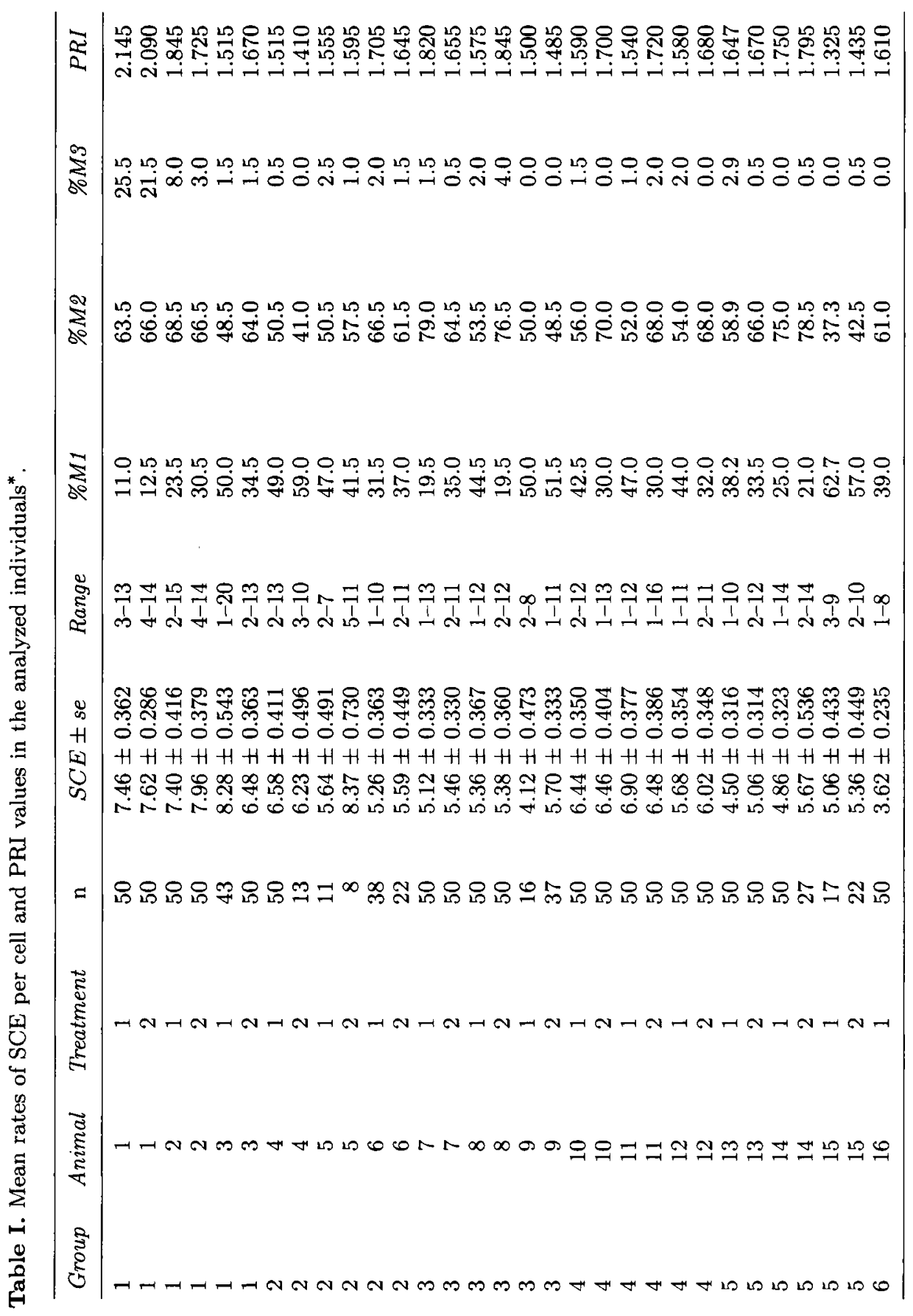


Sister-chromatid exchange frequencies in cattle

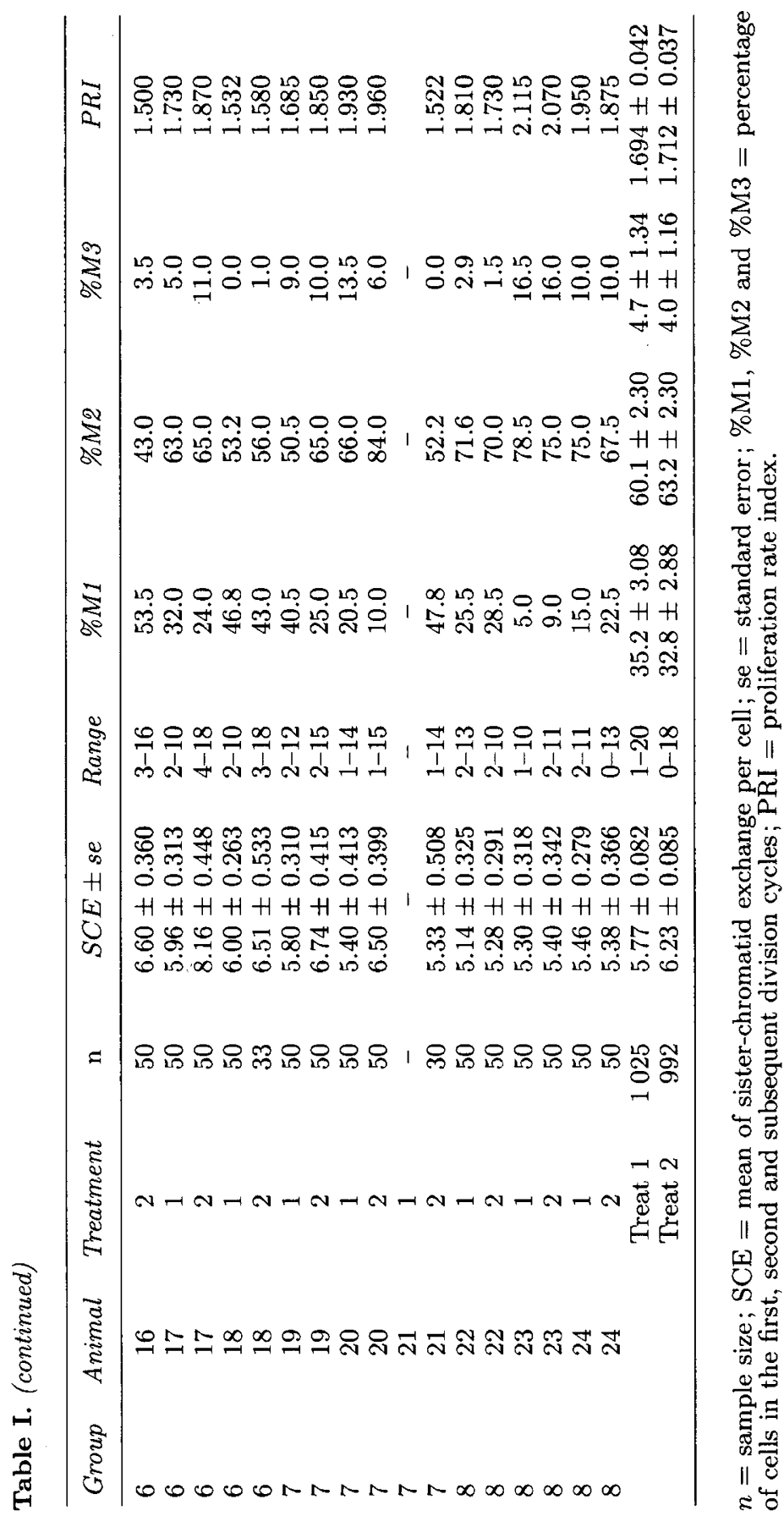


of the SCE residuals is shown in figure 1. When the Kolmogorov-Smirnov normality test was applied, the statistical value obtained $(0.069, p<0.01)$ indicated that the SCE frequency did not follow a normal distribution. Likewise, the residual variance was not homogeneous, as is demonstrated by the highly significant relationship found between the mean and the standard deviation from each analyzed combination of factors $(y=0.208 x+1.179, p<0.01$, where $y=$ sd and $x=$ mean).

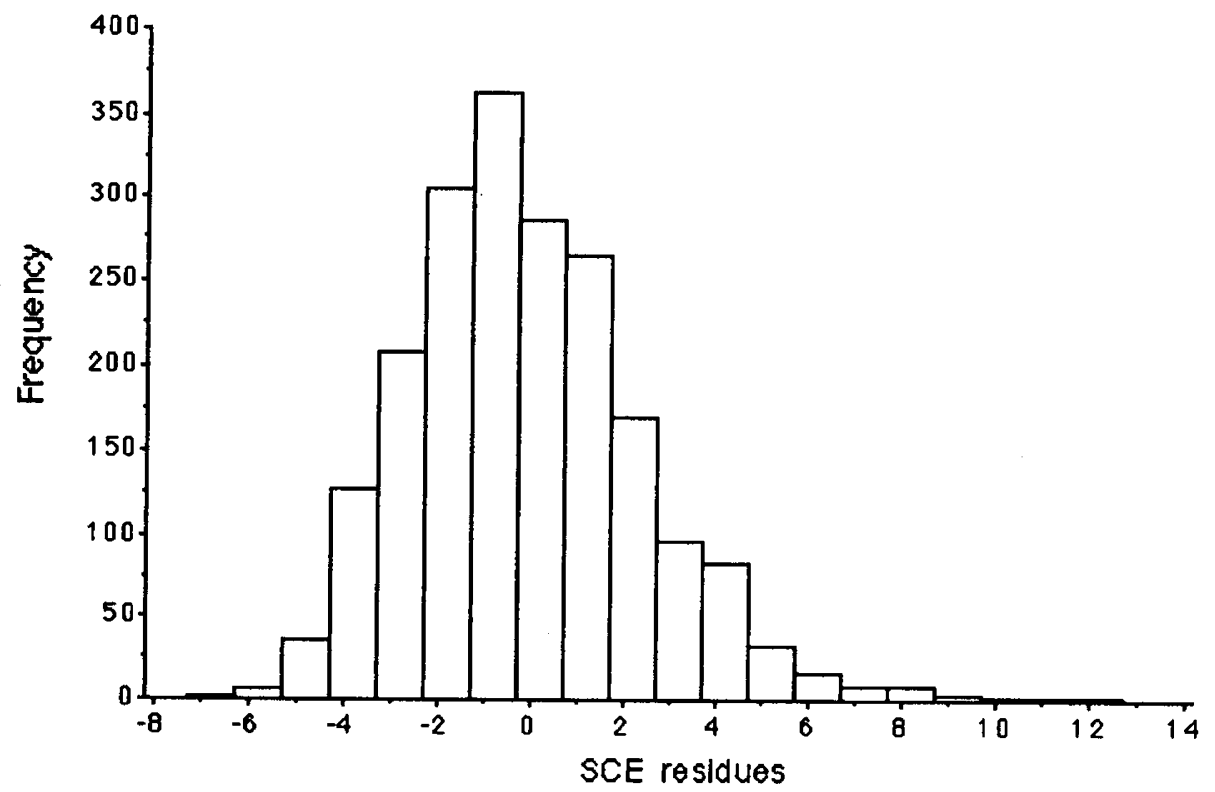

Fig 1. Histogram of the frequency distribution of SCE residuals.

The results of the tests indicated that data transformation had to be applied. In order to select the best transformation, 3 alternative theoretical probability distributions were evaluated in fitting the observed distribution of SCEs to either the normal, Poisson, or negative binomial distributions. The results of the goodness of fit tests are given in table II, and indicate which distributions do not significantly differ $(p>0.5)$ from the observed distribution of SCEs. As shown, the Poisson and negative binomial distributions were found to give a good representation of the within-treatment distribution of SCEs. The square-root transformation has been specifically recommended for these distributions (Erexson et al, 1983; Steel and Torrie, 1985). Therefore, this transformation was applied and, consequently, the character to be analyzed was $y=(\mathrm{SCE} / \mathrm{cell})^{1 / 2}$. Table III shows the results of the corresponding analysis of variance. As can be seen, group, animal and treatment factors manifest an important influence on the SCE yields. In addition, the individual-treatment interaction has a significant effect.

In order to investigate whether treatment 2 can reduce the residual variability, an $F$-test (Peña, 1988) was applied to compare both treatment variances. The residual variances for treatment 1 and 2 were 5.822 and 6.406 with 1024 and 991 degrees 
Table II. Distribution of SCE residual frequencies in each analyzed individual-treatment level*.

\begin{tabular}{|c|c|c|c|c|c|}
\hline Group & Animal & Treatment & \multicolumn{3}{|c|}{ Theoretical Distribution } \\
\hline 1 & 1 & 1 & - & $\mathrm{P}$ & - \\
\hline 1 & 1 & 2 & - & - & - \\
\hline 1 & 2 & 1 & - & $\mathrm{P}$ & NB \\
\hline 1 & 2 & 2 & - & $\mathrm{P}$ & - \\
\hline 1 & 3 & 2 & $\mathrm{~N}$ & $\mathrm{P}$ & - \\
\hline 2 & 4 & 1 & $\mathrm{~N}$ & $\mathbf{P}$ & NB \\
\hline 3 & 7 & 1 & - & $\mathrm{P}$ & NB \\
\hline 3 & 7 & 2 & - & $\mathrm{P}$ & - \\
\hline 3 & 8 & 1 & $\mathrm{~N}$ & $\mathrm{P}$ & NB \\
\hline 3 & 8 & 2 & - & $\mathrm{P}$ & NB \\
\hline 4 & 10 & 1 & - & $\mathrm{P}$ & - \\
\hline 4 & 10 & 2 & $\mathrm{~N}$ & $\mathrm{P}$ & NB \\
\hline 4 & 11 & 1 & $\mathrm{~N}$ & $\mathrm{P}$ & - \\
\hline 4 & 11 & 2 & - & $\mathbf{P}$ & NB \\
\hline 4 & 12 & 1 & $\mathrm{~N}$ & $P$ & NB \\
\hline 4 & 12 & 2 & - & $\mathbf{P}$ & - \\
\hline 5 & 13 & 1 & - & $\mathbf{P}$ & NB \\
\hline 5 & 13 & 2 & - & $\mathrm{P}$ & - \\
\hline 5 & 14 & 1 & - & $\mathrm{P}$ & NB \\
\hline 6 & 16 & 1 & - & $\mathrm{P}$ & - \\
\hline 6 & 16 & 2 & $\mathrm{~N}$ & $\mathbf{P}$ & - \\
\hline 6 & 17 & 1 & $\mathrm{~N}$ & $\mathbf{P}$ & - \\
\hline 6 & 17 & 2 & - & $\mathrm{P}$ & NB \\
\hline 6 & 18 & 1 & $\mathrm{~N}$ & $\mathrm{P}$ & - \\
\hline 7 & 19 & 1 & - & $\mathbf{P}$ & - \\
\hline 7 & 19 & 2 & $\mathrm{~N}$ & $\mathrm{P}$ & NB \\
\hline 7 & 20 & 1 & - & $\mathrm{P}$ & NB \\
\hline 7 & 20 & 2 & - & $\mathrm{P}$ & NB \\
\hline 8 & 22 & 1 & - & $\mathrm{P}$ & - \\
\hline 8 & 22 & 2 & $\mathrm{~N}$ & $\mathbf{P}$ & - \\
\hline 8 & 23 & 1 & - & $\mathrm{P}$ & - \\
\hline 8 & 23 & 2 & - & $\mathrm{P}$ & NB \\
\hline 8 & 24 & 1 & - & $\mathrm{P}$ & - \\
\hline 8 & 24 & 2 & - & $\mathbf{P}$ & NB \\
\hline
\end{tabular}

* Only individuals and treatments where 50 mitoses could be counted have been considered; $\mathrm{N}=$ normal $; \mathrm{P}=$ Poisson $; \mathrm{NB}=$ negative binomial.

of freedom, respectively. The result of this test $(F=1.10, p<0.05)$ shows that treatment 2 variance was higher than treatment 1 variance.

Finally, a regression analysis between the PRI values and mean SCE frequencies (on the transformed scale) from each individual-treatment combination was carried out. Neither the regression line $(y=0.139 x+2.148)$ nor the correlation value $(r=0.122)$ were significant $(p>0.05)$. Likewise, the relationship between the exchange frequency and percentage of cells in their second or third cycle of division 
Table III. Analysis of variance corresponding to transformed data $\left(y=[\mathrm{SCE} / \mathrm{cell}]^{1 / 2}\right)^{\mathrm{a}}$.

\begin{tabular}{lrrrrrr}
\hline$S V$ & $D F$ & $M S$ & & F & $E L$ \\
\hline Individual & 23 & & & & \\
$\quad$ Group & 7 & 7.057 & 7.064 & $(p<0.01)$ & Animal \\
$\quad$ Animal within group & 16 & 0.999 & 3.770 & $(p<0.01)$ & Residual \\
Treatment & 1 & 5.937 & 6.724 & $(p<0.05)$ & Individual $\times$ treatment \\
Individual $\times$ treatment & & & & & Residual \\
(or experimental error) $^{\mathrm{b}}$ & 22 & 0.883 & 3.332 & $(p<0.01)$ & \\
Residual (or sampling error) & 1970 & 0.265 & & & \\
\hline
\end{tabular}

${ }^{\mathrm{a}} \mathrm{SV}=$ Source of variation $; \mathrm{DF}=$ degrees of freedom $; \mathrm{MS}=$ mean square $; F=F$ observed statistic; $\mathrm{EL}=$ error line, indicates which error term was used to compute $F$ (Dagnelie, $1969) ;{ }^{b}$ one individual $\times$ treatment combination is missing.

was analyzed. The results of these analyses $(r=0.266$ and $r=-0.051$ respectively, with $p>0.05$ in both cases) indicate that SCE frequency was not correlated with any cell cycle.

\section{DISCUSSION}

\section{Distribution of exchanges}

Traditionally, a great number of researchers suggest that sister-chromatid exchanges fit a Poisson model when the distributions of exchanges is studied in the totality of individuals analyzed (Di Berardino and Shoffner, 1979; Gutierrez and Calvo, 1981; MacFee and Long, 1982; Di Berardino et al, 1983; Margolin and Shelby, 1985; Swierenga et al, 1991). Only Iannuzzi et al $(1988,1991)$ disagree with this suggestion, but do not propose an alternative distribution. When the probability to produce 1,2,3 or more SCEs in the same chromosome was investigated, McFee and Sherrill (1979) found that the distribution followed a Poisson model for humans and cattle, but not for porcine and ovine species. Finally, Di Berardino and Shoffner (1979) as well as Izquierdo and Sinues (1989) described the average number of SCEs per cell by means of a normal pattern; the present work found the opposite result $(p<0.05)$.

To our knowledge, the only previous research on residual distribution was carried out by Hirsch et al (1984). In their study, the Poisson distribution was found to provide a very poor representation of the within-persons distributions of SCE. In contrast, the negative binomial distribution was found to give a good representation of the within persons distribution. In the present work, both distributions were expressed but the Poisson model gave a better fit. The distributions differ substantially in their biological significance. Under the Poisson distribution, SCEs are assumed to occur independently, with a constant probability for all cells. In contrast, the negative binomial distribution, which is an alternative to the Poisson, arises when the probability of observing 1 SCE is allowed to vary from cell to cell (Hirsch et al, 1984). Therefore, the different preponderance of negative binomial and 
Poisson distributions existing between Hirsch et al (1984) and our results may be due to differences between species in relation to the sensitivity of their lymphocyte populations.

\section{Sources of variation in SCE frequency}

The results of the analysis of variance indicate that group, animal and treatment factors have a significant effect on SCE rates.

\section{Group and animal factors}

The significant influence of the group factor indicates that some of the controlled and/or uncontrolled factors can modify the SCE yield. Many papers have been published on the influence of these factors on humans (for a review, see Wulf, 1990) but this influence should be considered in further investigations on cattle since such studies are scarce.

Within each group, animals showed significant differences in relation to their SCE frequencies. The majority of authors who studied this factor (Di Berardino and Shoffner, 1979; Lindblad and Lambert, 1981; Lamberti et al, 1983; Leibenguth and Thiel, 1986; Tucker et al, 1988; Miller, 1991) agree with our results. It has been suggested that the main cause of animal variation may be differing sensitivity to DNA damage and SCE formation among lymphocyte subpopulations (Lindblad and Lambert, 1981; Santesson, 1986; Miller, 1991). However, the theories about SCE frequency differences among lymphocyte populations are contradictory. Lindblad and Lambert (1981) and Lamberti et al (1983) believe that these differences arise from their different rates of cell proliferation, since they found significant correlations between SCE frequency and the percentage of cells in second division $(r=0.56, p<0.01$ and $r=0.50, p<0.01$, respectively) and between the SCE frequency and the percentage of cells in third division $(r=-0.65, p<0.01$ and $r=-0.69, p<0.01$, respectively). In addition, Lamberti et al (1983) also calculated the PRI value and found a negative correlation $(r=-0.70, p<0.01)$ between this index and the SCE frequency. In contrast, our results showed a non-significant correlation between PRI and SCE values, and neither the percentage of cells in second division nor that in third division appeared to influence the SCE frequency in a significant way. Although connections between cellular kinetics and SCE rates were also reported by Bochkov et al (1984) and Miller (1991), we agree with other authors (Giulotto et al, 1980; Loveday et al, 1990; Steinel et al, 1990) that the incidence of SCE appears to be independent of the proliferation properties of cells.

\section{Treatment factor}

We introduced 2 different $\mathrm{BrdU}$ treatments in order to reduce the residual variance as much as possible. In the standard method, an identical BrdU concentration is added to all the cultures, since, as Davidson et al (1980) pointed out, the concentration of $\mathrm{BrdU}$ in the medium, rather than the amount of $\mathrm{BrdU}$ available per cell, is the major factor in determining the frequency of SCEs. However, Stetka and Carrano (1977) considered that the SCE frequencies depend upon the number 
of BrdU molecules available per cell and not solely upon molarity. An alternative method is to fix the concentration of lymphocytes added at the beginning of the culture (basis of treatment 1). However, since there are individual differences in the stimulation response to the mitogen and the proliferative capacity of the cells, the amount of cells in division at the moment of BrdU addition could have varied substantially. For this reason, a cellular counting after $46 \mathrm{~h}$ of culture was introduced to adjust the amount of BrdU added per cell in the cultures of treatment 2.

The PRI obtained was surprisingly higher than expected; on average, the cells had gone through 3 replication cycles in $46 \mathrm{~h}(3.038 \pm 0.42)$. Because of the faster PRI, a greater quantity of BrdU was added to treatment 2 cultures in comparison to treatment 1 cultures, explaining the significant difference between their mean values ( $5.77 \pm 0.082$ and $6.23 \pm 0.085 \mathrm{SCE} /$ cell, respectively, on the non-transformed scale). Furthermore, differences between both treatments were not found in all individuals, depending on the $\mathrm{BrdU}$ dose added to treatment 2, which explains the significant effect of the individual-treatment interaction.

Reduction of the residual variance would be possible if the determining factor is, as Stetka and Carrano (1977) argue, the number of BrdU molecules available per cell. Treatment 1 cultures, receiving the same amount of BrdU, will then show a greater variability than treatment 2 cultures, in which BrdU dose has been adjusted according to cellular density, even in each replicate. The results of the comparison of variances indicate that treatment 2 variance is greater than treatment 1 variance. Therefore, it is clear that our results agree with those of Davidson et al (1980); the number of $\mathrm{BrdU}$ molecules available per cell has little influence in relation to its molarity.

\section{REFERENCES}

Arruga MV, Catalán J, Moreno C (1992) The effect of chloramphenicol on sisterchromatid exchange (SCE) in bovine fibroblasts. Res Vet Sci 52, 256-259

Basrur PK, Gilman JPW (1964) Blood culture method for the study of bovine chromosomes. Nature 204, 1335-1337

Bochkov NP, Chebotarev AN, Filippova TV, Platonova VI, Stukalov SV, Debova GA (1984) Alterations in the baseline sister-chromatid exchange frequency in human lymphocyte culture following a number of cell divisions. Mutat Res 127, 149-153

Dagnelie P (1969) Théorie et méthodes statistiques. Applications agronomiques. Duculot, Gembloux

Davidson RL, Kaufman ER, Dougherty CP, Ouellette AM, Difolco CM, Latt SA (1980) Induction of sister-chromatid exchanges by BrdU is largely independent of the BrdU content of DNA. Nature 284, 74-76

Di Berardino D, Shoffner RN (1979) Sister-chromatid exchange in chromosomes of cattle (Bos taurus). J Dairy Sci 62, 627-632

Di Berardino D, Iannuzzi L, Fregola A, Matassino D (1983) unromosome instability in a calf affected by congenital malformation. Vet Rec 30, 429-432

Erexson GL, Wilmer JL, Kligerman AD (1983) Analyses of sister-chromatid exchange and cell-cycle kinetics in mouse T- and B-lymphocytes from peripheral blood cultures. Mutat Res 109, 271-281 
Giulotto E, Mottura A, Giorgi R, Carli L, Nuzzo F (1990) Frequencies of sisterchromatid exchanges in relation to cell kinetics in lymphocyte cultures. Mutat Res $70,343-350$

Gutierrez C, Calvo A (1981) Approximation of baseline and BrdU-induced SCE frequencies. Chromosoma 83, 685-695

Harvey WR (1987) LSMLMW Computing procedures and applications. Columbus, Ohio 43210

Hirsch B, McGue M, Cervenka J (1984) Characterization of the distribution of sister-chromatid exchange frequencies: implications for research design. Hum Genet $65,280-286$

Iannuzzi L, Perucatti A, Di Meo GP, Ferrara L (1988) Sister-chromatid exchange in chromosomes of river buffalo (Bubalus bubalis L). Caryologia 41, 237-244

Iannuzzi L, Di Meo GP, Perucatti A, Ferrara L (1990) Mitomycin C-induced sisterchromatid exchange in $\mathrm{X}$ chromosomes of bovidae. J Heredity $81,78-80$

Iannuzzi L, Di Meo GP, Perucatti A, Gustavsson I (1991) Sister-chromatid exchange in chromosomes of cattle from three different breeds reared under similar conditions. Hereditas 114, 201-205

Ivett JL, Tice RR (1982) Average generation time: a new method of analysis and quantitation of cellular proliferation kinetics. Environ Mutagen 4, 358

Izquierdo M, Sinues B (1989) Biomonitoring of genotoxicity induced by smoking. Hereditas 111, 201-203

Lamberti L, Bigatti P, Ardito G (1983) Cell kinetics and sister-chromatid exchange frequency in human lymphocytes. Mutat Res 120, 193-199

Leibenguth F, Thiel G (1986) BrdU- and EMS-dependent sister-chromatid exchange and chromosomal breaks in cattle. Arch Zootec 35, 301-30

Lindblad A, Lambert B (1981) Relation between sister-chromatid exchange, cell proliferation and proportion of B and T cells in human lymphocyte cultures. Hum Genet 57, 31-34

Loveday KS, Anderson BE, Resnick MA, Zeiger E (1990) Chromosome aberration and sister-chromatid exchange test in Chinese hamster ovary cells in vitro. V: Results with 46 chemicals. Environ Mol Mutagen 16, 272-303

Margolin BH, Shelby MD (1985) Sister-chromatid exchanges: A reexamination of the evidence for sex and race differences in humans. Environ Mutagen 7, 63-72

McFee AF, Sherrill MN (1979) Species variation in 5-bromodeoxyuridine-induced sister-chromatid exchanges. Mutat Res 62, 131-138

McFee AF, Long SE (1982) Sister-chromatid exchanges in the active and inactive $\mathrm{X}$ chromosomes. Chromosoma 87, 359-362

McFee AF, Sherrill MN (1983) Sister-chromatid exchanges induced in swine lymphocytes by chronic oral doses of dimethylbenzanthracene. Mutat Res 116, 349-35 Miller K (1991) Sister-chromatid exchange in human B- and T-lymphocytes exposed to bleomycin, cyclophospamide, and ethylmethanesulfonate. Mutat Res 247, 175182

Nordic Study Group (1990a) A Nordic database on somatic chromosome damage in humans. Mutat Res 241, 325-337

Nordic Study Group (1990b) An inter-Nordic prospective study on cytogenetic endpoints and cancer risk. Cancer Genet Cytogenet 45, 85-92 
Peña D (1988) Estadística. Modelos y métodos. Alianza editorial, Madrid Perry P, Wolff S (1974) New Giemsa method for the differential staining of sister chromatids. Nature 251, 156-158

Santesson B (1966) Different baseline sister-chromatid exchanges levels in density fractionated human lymphocytes. Hum Genet 73, 114-118

Sorsa M, Autio K, Abdondandolo A, Carbonel E, Demopoulos N, Garner C et al (1992) Evaluation of in vitro cytogenetic techniques in nine European laboratories in relation to chromosomal endpoints induced by three model mutagens. Mutat Res (in press)

Steel RGD, Torrie JH (1985) Bioestadística. Principios y procedimientos. McGrawHill, Bogotá

Steinel HH, Arlauskas A, Baker RSU (1990) SCE induction and cell-cycle delay to toxaphene. Mutat Res 230, 29-33

Stetka DG, Carrano AV (1977) The interaction of Hoechst 33258 and BrdU substituted DNA in the formation of sister-chromatid exchanges. Chromosoma 63 , 21-31

Swierenga SHH, Heddle JA, Sigal EA, Gilman JPW, Brillinger RL, Douglas GR, Nestman ER (1991) Recommended protocols based on a survey of current practice in genotoxicity testing laboratories, IV. Chromosome aberration and sisterchromatid exchange in Chinese hamster ovary, V79 Chinese hamster lung and human lymphocyte cultures. Mutat Res 246, 301-322

Takehisa S (1982) Induction of sister-chromatid exchanges by chemical agents. In: Sister-chromatid exchange (S Wolff, ed) John Wiley, New York, 87-147

Tucker JD, Ashworth LK, Johnston GR, Allen NA, Carrano AV (1988) Variation in the human lymphocytes sister-chromatid exchange frequency: Results of a longterm longitudinal study. Mutat Res 204, 435-444

Wulf HC (1990) Monitoring of genotoxic exposure of humans by the sisterchromatid exchange test. Methodology and confounding factors. Dan Med Bull 37, $132-143$ 